University of Denver

Digital Commons @ DU

$1-2008$

\title{
A Linguistic Analysis of Chat Reference Conversations with 18-24-Year-old College Students
}

Jack M. Maness

University of Denver

Follow this and additional works at: https://digitalcommons.du.edu/libraries_facpub

Part of the Library and Information Science Commons, and the Linguistics Commons

\section{Recommended Citation}

Maness, J. M. (2008). A linguistic analysis of chat reference conversations with 18-24 year-old college students. Journal of Academic Librarianship, 34(1), 31-38. https://doi.org/10.1016/j.acalib.2007.11.008

\section{(c) (i) $\ominus$}

This work is licensed under a Creative Commons Attribution-NonCommercial-No Derivative Works 4.0 International License.

This Article is brought to you for free and open access by the University Libraries at Digital Commons @ DU. It has been accepted for inclusion in University Libraries: Faculty Scholarship by an authorized administrator of Digital Commons@DU. For more information, please contact jennifer.cox@du.edu,dig-commons@du.edu. 


\section{A Linguistic Analysis of Chat Reference Conversations with 18-24-Year-old College Students}

\section{Comments}

Published version may be found at: https://doi.org/10.1016/j.acalib.2007.11.008

\section{Publication Statement}

Copyright held by the author or publisher. User is responsible for all copyright compliance. 


\title{
A Linguistic Analysis of Chat Reference Conversations With 18-24 Year-Old College Students
}

\author{
Jack M. Maness \\ University Libraries \\ University of Colorado at Boulder \\ 184 UCB \\ 1720 Pleasant St. \\ Boulder, CO 80309 \\ 303-492-4545 \\ jack.maness@colorado.edu
}

\begin{abstract}
Thirty-one chat reference conversations were linguistically analyzed, compared to twenty-three instant messaging (IM) conversations held between students, and further correlated to students' satisfaction with the reference interaction. Conversations between librarians and students in chat reference are more formal than those solely involving students, and the use of some linguistic patterns are correlated to user satisfaction.
\end{abstract}

\section{Language and "Chat Reference"}

Chat reference, here defined as a subset of virtual reference (which would further include email reference) is an increasingly common service offered by academic libraries to their patrons. It enables librarians to provide synchronous reference service online by "chatting" with patrons, and in many cases sharing files and web-pages through special software. Recent findings suggest the use of chat software and instant messaging (IM) among Americans of undergraduate age to communicate among one another is very prevalent and is increasing; ${ }^{1}$ libraries providing reference through similar media, then, is rational and appropriate. 
It has been widely noted in librarianship and other fields that the language used by patrons in these chat reference and IM conversations is unique in that it is of a more spoken, informal genre and style than most written forms of communication. As a form of computer-mediated-communication (CMC), it is nuanced and unique in this regard. Studies of CMC are numerous, but for the purposes of this linguistic analysis, three important facets of CMC are relevant: emoticons (and similar compensations for the lack of non-verbal cues); CMC abbreviations; and CMC acronyms. These will be defined and discussed in the methodology.

The observation that chat conversations are perhaps less formal than conventional written language has lead to many guidelines and suggested practices in regards to librarians' use of language in such environments. It is often suggested that librarians attempt to strike a balance between formal and informal language; that a too informal genre undermines credibility and a too formal genre inhibits rapport building and communication. ${ }^{2}$ These suggestions are particularly emphasized when librarians are working with young adult patrons and undergraduates. While valuable, most such suggested practices are anecdotal.

Little to no research has been conducted that specifically analyzes the linguistic formality of these chat conversations. There is much interesting and important qualitative investigation into the larger issue of communication patterns in chat reference, ${ }^{3}$ but no specific quantitative analysis of linguistic style or genre. This study will attempt to construct a linguistic profile of chat reference with 18-24 year old students, correlate the profile to user satisfaction, and base suggested practices for language use in chat reference on this profile and correlation. A profile and measure of satisfaction such 
as this could assist librarians unfamiliar with $\mathrm{CMC}$ conventions in providing effective service, and validate the practices of those familiar with such conventions.

\section{Language Style and Genre}

Analyzing language, a dynamic form of human expression, is inherently difficult. Criteria that seek to categorize linguistic phenomenon can seem arbitrary and subjective. This difficulty is assumed in this study, and the discussion of language's style and genre is not intended to further linguistic research. It is intended to serve as a method by which librarians might further understand the language they and their patrons use in chat reference. The factors by which the lexical issues at hand are categorized are chosen so that they might be most beneficial to the research of librarianship, not necessarily to linguistics research.

Two linguistic factors are under analysis: style and genre. They are intrinsically interrelated factors, and are not treated separately. But it is useful to define them for the purposes of the study. "Style" is meant to refer to the formality of language, moving along a continuum from informal to formal. "Genre" is meant to refer to the general characteristics of spoken versus written communication. ${ }^{5}$

Generally, spoken genre tends to be less formal in style, and written genre more formal. But it is important to note that "no dimension defines and absolute spoken/written distinction." ${ }^{\prime 6}$ Moreover, the dimensions that do provide distinctions are situational; the formality of language, spoken or written, depends on many factors, including the speaker/writer's interlocutor and the relationship between them, and the environment in which the language is being used (professional, academic, intimate, etc.). 
But it is recognized that even these situational factors do not provide absolute distinctions: "[S]peakers and writers sometimes thwart the situational forces operating in each mode and produce discourse that is atypical for that mode."

This study hypothesizes that chat reference CMC occupies a certain middle ground between spoken and written genres and formal and informal style and is more formal than student-to-student IM conversations. It further supposes that the use of some CMC tokens is positively correlated to student satisfaction levels. In some ways chat reference is more like written genre (most obviously it is processed visually and not auditorially), in some ways it is more spoken (it is synchronous and dialogical, whereas written language is more often asynchronous). And, in some ways it is formal, in others, informal. The reality is that interlocutors can, within a few minutes, utilize a vast array of linguistic tools and nuances; a formal conversation can become informal very quickly, and just as quickly revert to a more formal style.

The impetus of this study is to determine how linguistically formal these chat reference conversations are, and to what extent the formality of the language used by the librarian is correlated to patron satisfaction with the librarian. This study will provide a profile of chat reference conversations, compare it to a profile of student-to-student IM conversations, analyze how language use is correlated to user satisfaction, and recommend best practices based on those correlations.

\section{Footing}


An important situational dimension at work in this comparative analysis is "footing." "Footing" is a term used to describe the social relationships between individuals, and it has been widely noted that writers and speakers' linguistic styles are influences by these relationships. Many factors are included in these relationships, including the power differential between the interlocutors (superior speaking with a subordinate versus two peers speaking together), whether they are intimate with each other or are strangers, and whether the relationship itself is formal (e.g. professional colleagues) or informal (neighbors, friends, etc.). It should also be noted that footing is also dynamic and subject to sudden changes; it is not set once at the outset of a dialog, but is continuously redefined throughout. ${ }^{8}$

How footing affects the current linguistic analysis is ostensibly that the librarianto-student conversations should be more formal than the student-to-student conversations. There is a possible perceived power difference in librarian-to-student conversations that could affect language usage (the librarian, representing the institution to which the student has approached for help, may be perceived as more powerful by the student), and the relationship is also more formal and more impersonal. Generally, these footings lead to more formal linguistic structures, and this relatively more formal language is expected in the librarian-to-student transcripts.

\section{Data}

Data discussed in this study are from two distinct sources. The first source was a paper by Naomi S. Baron in 2004 that reported the findings of a study of twenty-three undergraduate students' IM conversations at American University. ${ }^{9}$ These data were 
both collected and analyzed by Baron, who did not contribute to this study other than the publication of her cited paper.

The second source was chat reference conversations provided by AskColorado, a state-wide multi-type library collaborative services administered through the Colorado

State Library. ${ }^{10}$ During the time these sessions occurred, AskColorado was staffed by over 250 library personnel from over 50 libraries across Colorado, averaging 3,500 sessions per month. ${ }^{11}$ The conversations were held between November 2004 and June 2005, and each student participant indicated in a survey following the conversation that they were college or university students, 18-24 years old, and rated the librarians as either "very helpful" or "not helpful." The sample in this study was limited to the transcripts that could be definitively associated with survey results. ${ }^{12}$

\section{Methodology}

Relying heavily upon but slightly expanding Baron's lexical analysis methods, this study analyzed the thirty-one chat reference conversations by tabulating the number of words written by patron and librarian; the number of "scripted" words used by the librarian; contracted versus un-contracted lexical pairs; CMC abbreviations; CMC acronyms; emoticons and other non-verbal compensations; the extent to which capitalization and punctuation rules were observed; and how often patrons and librarians self-corrected for spelling or grammar.

\section{Words}


A simple tabulation of the number or words written by patron and librarian was done, following Baron's model. The number of the librarians' words that were "scripted" was also tabulated, something not pertinent to Baron's study. Scripted words are provided by the chat reference software AskColorado uses, and are therefore considered distinct from the librarians' words. Interestingly, while the patron would perceive the scripted words as the librarian's, the librarian would not. The importance of analyzing scripted versus non-scripted words is illustrated by Radford's finding that scripts act as "relational barriers," facets of chat conversations that typically inhibit communication effectiveness. $^{13}$

\section{Contracted versus non-contracted lexical pairs}

Again using Baron's model, this study tabulates how often a patron or librarian uses a contraction versus when they do not use a contraction, even when it is possible or

even common in offline written communication to do so. This tabulation is meant to help distinguish style and genre as one would expect that CMC would provide great impetus for the frequent use of contractions, as a time-saving and type-saving effort.

It is difficult to absolutely determine what contractions best address this measure of formality. Obvious contractions are for lexical pairs when a pronoun is followed by a verb (e.g. "I am," “you are," "it is," etc.). Typically, as in these examples, pronouns followed by verbs are counted when they are not contracted. "I have" is an interesting dilemma, however. "I have" as a part of the verb-phrase "I have been" is counted, whereas "I have" followed by the infinitive verb is not (e.g. "I have to go.") The 
rationale is that "I've been" is commonly contracted, but "I've to go" is not. It appears to the author that this is true in common American English usage.

Another notable exception to counting non-contracted lexical pairs is when a common noun is followed by the verb "is." For example, while it might be common to write, "The cat's in the bedroom," it is not typical to write "The house's on this street." Because the array of possibilities is so vast in the case of common nouns and a state of being verb, they are typically not counted as non-contracted pairs.

\section{CMC abbreviations and acronyms}

The tabulation and definition of these forms of communication follows the

methodology of Baron. CMC abbreviations were defined as

"[a]bbreviations that appear to be distinctive to CMC communication. Excluded from this tabulation are abbreviations that although appearing in $\mathrm{CMC}$ messages, are also part of common offline written usage (e.g. hours $=$ hrs) or are direct representations of spoken usage (e.g., cuz = because). Admittedly, the line between common offline and CMC-specific usage is sometimes difficult to draw (e.g. $b / c$ for because was included in the tally of CMC abbreviations, where as prob for problem was not). ${ }^{14}$

This study followed this methodology as closely as possible, and the definition for CMC acronyms was similarly constructed. Common acronyms, such as "UN" (for United Nations) was not considered, whereas "lol" (for "laughing out loud") was considered a CMC acronym.

A further note on the difficulty in determining whether an acronym or an abbreviation is $\mathrm{CMC}$-specific is that $\mathrm{CMC}$ tokens such as these are making their way into common offline usage, both spoken and written in some cases. Indeed, as society 
continues to employ more frequent use of $\mathrm{CMC}$, the delineation between $\mathrm{CMC}$, written, and spoken communication could become increasingly less distinctive.

Despite this difficulty, the use of these CMC-specific acronyms and abbreviations is here thought to provide a good measure of the style and genre of the language in chat reference. One would expect that the more frequently they are used, the more informal the linguistic situation, and vice versa.

\section{Emoticons and other non-verbal compensations}

While Baron tabulated emoticons, this study expanded the category to include similar tokens meant to compensate for the lack of non-verbal cues in CMC. Emoticons are symbols that most often are meant to stand for facial expressions (e.g., :) or :-) symbolize a smiling face, thus are used to indicate pleasure or amusement). Other methods of compensating for facial and other non-verbal communication are the use of ellipses to indicate thought, hesitation, or simply a forthcoming continuation of a thought (e.g, "I think...I think maybe your best bet is to...come into the library...."); the use of a dash to do the same; the use of capitals to stress meaning or importance (e.g. "THAT IS NOT WHAT I WANTED”); the use of multiple-punctuation to emphasize similar meanings or importance (e.g., "That is not what I wanted!!!”); and the use of utterances (e.g., “oohh” or “aahh”).

There are similar issues vis a vis the somewhat arbitrary categorization of these non-verbal compensations as there are with acronyms and abbreviations. Most notably, the ellipse and dash are common to offline written communication, as are in some cases capitals and double-punctuation. However, they are largely used in most written 
communication in only informal situational contexts. Formal writing rarely allows for the use of ellipses and dashes in the manner here noted, as does it for capitals and doublepunctuation.

\section{Grammatical structure}

The tabulation of grammatical issues in the current study does veer from the lexical nature of the rest of the study, but it is considered too important in regards to style and genre to be omitted. A rougher, more cursory tabulation of capitalization and punctuation was compiled; librarians and patrons were categorized as using correct punctuation and capitalization, not doing so, or at times doing so and at others not doing so. Admittedly, a finer quantitative analysis of these grammatical uses would be beneficial, but such a general description of it is also useful for the purposes of this study. It is also noteworthy that it was not difficult to categorize librarians or patrons in this regard. The three categories are surprisingly distinctive in the transcripts.

Another aspect of grammar that was tabulated was how frequently a librarian or patron corrected their spelling or grammatical errors. This tabulation is thought to illustrate the writer's perception of the formality of the situation, as is the use of capitals and punctuation.

\section{Results: Comparison of student-to-student versus librarian-to-student profiles \\ Baron's article "offers a linguistic profile of American college student IM conversations," and a cursory finding was that the profile is markedly more formal than what popular belief seems to hold. ${ }^{15}$ These results will offer a similar profile of}


American college student IM conversations with librarians, comparing this profile to Baron's as well as comparing the librarians' profile with the students'.

Writing of the same study in a subsequent publication, Baron further concluded that "when teenagers transition to college, they naturally shed some of their adolescent linguistic ways in favor of more formal writing conventions..."16 The study reported in this paper finds that comparable students further shed some of their adolescent linguistic devices as they chat with librarians. In some ways, the students are more formal when addressing librarians, and librarians, relative to students, are in some ways more formal and in some ways more informal. All together, the student-to-librarian conversation is markedly different from the student-to-student conversation, and could be seen as being more formal in its style, more written in its genre.

\section{General}

Baron's corpus included 11,718 words in twenty-three distinct conversations. ${ }^{17}$ This study includes 6,787 words in thirty-one distinct conversations. Of the 6,787 words, librarians were responsible for 4,376, of which 836 were scripted. The remainder $(2,411$ words) was the patrons' lexicon.

Considering that the 11,718 words included in the student-to-student conversations were derived from twenty-three distinct conversations, and the 6,787 words in this study were derived from thirty-one conversations, it is noteworthy that the librarian-to-student conversations were terse in comparison. A possible reason for this is that the librarians and students are sharing many other bits of information (118 web pages are shared in the course of thirty-one conversations). Essentially, it is obvious that the 
intent of the student-to-student conversations is the conversation itself, whereas the primary intent of the librarian-to-student conversations is the sharing of resources, and the conversation is used to facilitate this process.

\section{Contracted versus non-contracted lexical pairs}

Baron found that $65.3 \%$ of potential contractions were contracted. ${ }^{18}$ This finding was unexpected as one would assume that the time-saving aspects of using contractions in English would be given added reinforcement by the CMC media.

This study found that a very similar $62.2 \%$ of these lexical pairs were contracted. Further, it is interesting to note that the students contracted more often than in the Baron study $(68.1 \%)$, and the librarians actually contracted less often $(58.9 \%)$.

If the decision to contract lexical pairs is given as a reason for citing the relative formality of language in these CMC environments, these findings suggest that students are actually less formal when chatting with librarians than with each other and librarians are the most formal of the group. The latter was somewhat expected, the former unexpected. This facet of language is, however, but one of many when considering style and genre, and the differences are minimal. Essentially, this facet of the conversations suggests that student-to-student and librarian-to-student conversations are of similar formality.

\section{CMC Abbreviations}

Baron found thirty-one CMC abbreviations in 11,718 words. ${ }^{19}$ Though Baron does not analyze this by using a percentage of the corpus that were abbreviated in this 
manner, that percentage would be a fraction of one-percent. Similarly, this study found only five abbreviations, also a fraction of one-percent, an even smaller fraction. There was also a significant overlap in the abbreviations used (see Table 1).

[insert Table 1]

Both studies found a remarkably low frequency of CMC-abbreviated words. It is further interesting that none of the five abbreviations were used by librarians: all five were patron-initiated. If, then, the five are considered as generating from a corpus of 2,411 words (students only), the percentages of words that are abbreviated in the two studies are remarkably similar; students use such abbreviations $0.26 \%$ of the time when chatting with peers, and $0.21 \%$ of the time when chatting with librarians. The difference is negligible, and suggests that in this facet, student-to-student and student-to-librarian chat conversations have similar styles.

\section{CMC Acronyms}

If the facets of contracting lexical pairs and the use of CMC abbreviations yielded only minor distinctions between student-to-student and librarian-to-student conversations, it is in the facet of CMC acronyms where the divergence is seen.

While Baron's study found 90 acronyms,${ }^{20}$ this study found none. The most popular CMC acronym in student-to-student conversations was lol (laughing out loud), an increasingly common expression in modern English, which was used seventy-six times. The next most-common, ttyl (talk to you later), was used only five times.

There are several ways of analyzing this result. On the surface, it seems that the vast majority of the time students use an acronym, it is to indicate similar expressions: 
pleasure, delight, laughter, etc. It could be that the use of lol is much more likely with student-to-student conversations as they are more intimate and personal (and perhaps more pleasing in turn), and that excluding this acronym from the analysis would yield another result of no significant difference between the linguistic profiles of student-tostudent and librarian-to-student.

However, the complete absence of any acronyms in the study at hand was quite unexpected. There were certainly moments where the student was obviously experiencing delight or amusement, but did not choose to use lol as a way of expressing it, and there were of course plenty of other opportunities to use acronyms. It is reasonable to conclude from this finding that students are in fact more formal, at least in regards to the use of acronyms, with librarians than they are with one another. To some degree, they drop the rather informal use of such tokens, perhaps an indication of the social variance between the two situations.

\section{Emoticons}

The final comparison to Baron's study is the use of emoticons. Forty-nine instances of nine different emoticons were found in student-to-student conversations, whereas only six instances of two different emoticons were found in the librarian-tostudent conversations (see Table 2).

[insert Table 2]

Similar to the lack of acronyms, the librarian-to-student conversations lack the use of emoticons. In both cases, it is worth reiterating, their prevalence is lower than one might expect, but it is even lower in librarian-to-student conversations. 
It seems that a comparison of student-to-student and librarian-to-student conversations, in terms of linguistic formality, yields a marked difference; there is a dramatic lack of some CMC communication patterns in the librarian-to-student conversations. This fact may indicate that the social difference of the relationship is indeed perceived by the librarians and students, and the style and genre of the language used reflects that very awareness. Students are more formal when chatting with librarians than with each other, and librarians are more formal than students. Both of these results confirm initial corresponding hypotheses.

\section{Other non-verbal compensations}

In an effort to provide a more complete and useful profile of chat reference conversations with 18-24 year olds, this study added categories not found in the Baron study. The category of "other non-verbal compensations" is intended to expand the emotion category in a way that will help librarians understand the linguistic characteristics of chat reference.

The non-verbal compensations include the use of the ellipse and dash as defined in the methodology; the use of capital letters to emphasize meaning; the use of doublepunctuation; and the use of utterances. Table 3 indicates the use of these tokens by librarians and students.

[insert Table 3]

The specific use of these compensators seems to differ greatly between students and librarians, though the general use of them is probably not as prevalent as one might 
expect. Less than eighty uses of them in almost 7,000 words do not suggest that chat reference conversations are replete with such informal tokens.

Nevertheless, it is interesting to note that while librarians use more non-verbal compensators, they use ellipses with an overwhelming frequency (83\% of total compensators). Students, conversely, use the ellipse only $53 \%$ of the time they use a compensator. Librarians seem to be fonder of utterances, and students of multiplepunctuation and capitals.

It could be surmised that this discrepancy is due to ellipses and utterances being more common in written (though informal) language than are other compensators, such as in fiction writing, and librarians are more familiar with these devices and make better use of them than do students. A student using capitals and punctuation to compensate, primarily for the lack of volume and tone in chat, is perhaps indicative of their familiarity with CMC.

Though none of these compensators can be considered part of formal writing, it is conceivable that the librarians' preferences among them are in fact a bit more formal (or at least more common) in offline writing, than students' preferences.

\section{Grammatical structure}

Students and patrons were categorized as following correct punctuation and capitalization (y), not doing so (n), or sometimes following these grammatical rules and sometimes not doing so $(y / n)$. Further, it was noted that on three occasions a writer began by following such rules, then abandoned doing so for the rest of the conversation. 
This facet of the conversations may in fact be the most revealing. Of thirty-one conversations, librarians used standard punctuation and capitalization in twenty-three of them. Students only did so in six conversations, and in three alternated between following and ignoring the rules. It is also very interesting to note that in the only three conversations where librarians did not follow standard grammar, they began by doing so but abandoned the practice, and in all of these conversations the students did not use standard grammar. It seemed the librarians began the conversations formally and gradually donned the more informal grammatical structure of their patrons.

It is unmistakable that in terms of proper use of punctuation and capitalization, librarians were much more formal than students.

\section{Results: Comparison of satisfied and unsatisfied patrons}

The following results are merely correlative. They can by no means be interpreted as causal; many factors cause a patron's satisfaction and perception of the librarians' helpfulness, some of which may not even be under librarians' control. But it is important to reference librarians to understand the correlative relationship between the language they use with 18-24 year-olds and those patrons' satisfaction with them. Only by understanding some of the role language plays in a chat reference interaction, can the

profession move beyond anecdotal recommendations and achieve truly empirically-based professional practices.

The following comparisons are intended to investigate the hypothesis that librarians should "mirror" the linguistic formality and corresponding CMC styles of their patrons. By comparing satisfied to unsatisfied students' language, and also the librarians' 
language in assisting them, an empirical analysis of how well a librarian mirrors their patrons' language, and how strong that practice is correlated to patron satisfaction, is possible.

\section{General}

Though the two groups of patrons did indeed indicate they were either "satisfied" or "unsatisfied" with the chat reference service, they also indicated their respective attending librarians were either "very helpful" or "not helpful." Thus, the groups are both an indication of the users' satisfaction with the individual librarians and the chat reference service more generally.

There were fifteen distinct conversations in the satisfied/helpful category, incorporating a total of 3,802 words. There were sixteen distinct conversations in the unsatisfied/unhelpful category, totaling 2,895 words. In both groups librarians accounted for between $63 \%$ and $64 \%$ of the words in the conversations. Thus, the relative loquaciousness of the librarians is in this study not correlated to patron satisfaction.

However, there is a distinct difference in the amount of scripted words librarians use in the two groups. Librarians rated as "very helpful" used 270 scripted words out of 2,445 total words (11.0\%). Librarians rated as "unhelpful" used 566 scripted words out

of 1,931 (29.3\%). Librarians rated favorably used scripts in a much smaller proportion of their lexicon. One possible interpretation is that the use of scripts is correlated to lower satisfaction levels in users, but it is important to note, among many factors, that the use of scripts is often in response to inappropriate behavior on behalf of the patron, a practice recommended by AskColorado's Policies and Procedures Subcommittee. Again, this 
study observes this phenomenon. There is no causal relationship that is determinable in this data.

Contracted versus non-contracted lexical pairs

"Very helpful" librarians contracted lexical pairs $65.9 \%$ of the time, and their patrons did so $70.4 \%$ of the time. Conversely, "unhelpful" librarians contracted $43.6 \%$ of the time, and their patrons did so $61.1 \%$ of the time. The "very helpful" librarians more closely mirrored the contraction patterns of their patrons.

This finding should not be underestimated. Non-contracted lexical pairs can seem diffident and officious in $\mathrm{CMC}$, and the use of contractions seems to be an appropriate way of building rapport without sacrificing standard language usage.

\section{CMC Abbreviations}

There was no correlation between the use of CMC abbreviations and student satisfaction in this data. In both groups patrons used three abbreviations and librarians used none.

\section{CMC Emoticons}

There was also no distinct finding for the use of emoticons. Only one librarian, rated as "very helpful" used an emoticon, and only five patrons total did so, three of them "satisfied" and two of them "unsatisfied." 


\section{Other non-verbal compensations}

There was, however, a great distinction in the use of other non-verbal compensators (see Table 4). "Very helpful" librarians made frequent use of such compensators, especially ellipses. "Unhelpful” librarians made scant use of compensators.

But the librarians in both cases were not necessarily "mirroring" the use of compensators in their patrons. "Unsatisfied" patrons used many diverse compensators, but "satisfied" patrons made moderate use of them, notably ellipses. In this case, "mirroring" does not seem to be the correlation to satisfaction, but the categorical use of compensators, most notably ellipses, regardless of patron use of them.

[insert Table 4]

There are many possible reasons why there is such a strong relationship between librarians' use of compensators and patron satisfaction but not the same relationship between patron use of them and their own satisfaction. One possible interpretation is that the use of ellipses in particular keeps the patron engaged in the conversation, that it fills silent times in such a way that informs the patron that the invisible librarian is still involved in the transaction. It does not matter, then, whether or not the patron informs the librarian that they are still involved; it only matters that the librarian informs the patron.

It could be that the "unsatisfied" patrons resorted to the use of non-verbal compensators out of frustration with the librarians' relative silence, or at least their inability to communicate with the patron effectively. "Satisfied" patrons use such compensators less often because they feel they are being heard and understood. In other 
words, one way of interpreting this data is that when librarians use compensators, especially ellipses, communication is more reliable and frequent, and patrons respond positively to this pattern.

This result, coupled with the use of contracted and non-contracted lexical pairs, does seem to suggest that "unhelpful" librarians do indeed employ a more formal, written style of language than "very helpful" librarians, and their patrons suffer for it. They appear to use too formal a language, treating the chat environment like a letter-writing medium instead of the unique and nuanced CMC that it truly is.

\section{Grammatical structure}

The final comparison between groups within this study is of their use of capitals and punctuation. As noted above, librarians overall tended to follow the standard use of such grammar more often than students. But it has yet to be determined how the relative use of such standardized, written English is correlated to patron satisfaction.

This result does indeed lend credence to the notion of "mirroring" a patron's language use. In all cases, librarians followed standard rules the vast majority of the time. In only three of the "very helpful" librarians' transcripts did they not use proper grammar, and in all three of those cases that had commenced the transaction doing so, abandoning the practice. And, in all three of those cases, the patrons did not use proper grammar. It seems the librarians were purposely mirroring their patrons. And their patrons were also

more formal overall, five of them using standard written rules and two of them oscillating between proper and improper punctuation and capitalization. In the "satisfied/very 
helpful" group, there was great consensus between librarian and patron as to the use of grammar.

All of the "unhelpful" librarians used proper grammar, almost unerringly. Their patrons, however, did not. Only one of the "unsatisfied" patrons did so, and only one used a mix of proper and improper grammar. There was little or no consensus in this component of language in this regard. It seemed the librarians were writing, but the patrons were speaking. A great disconnect was created in this spirit.

\section{Limitations of the study}

There are perhaps several limitations to this study. First, it is possible that the subjects in the Baron study and this are not comparable. Baron's students all attended a single, competitive, private university, whereas students in this study attended a wide array of community colleges, state colleges, and larger research universities. But is not possible to draw legitimate assumptions in this regard; while it could be that the students at American University would be more formal in writing than the students in this study, due to their educational background, it could also be that they would be less formal, given their possibly greater experience with CMC. An understanding of this issue is simply not available. What is known is that they are demographically similar in other ways: age, students in higher education, and at least some familiarity with CMC.

It is also conceivable that the students in this study are self-reporting incorrectly. There is no control on how the students indicated their age and school status.

There is also a difference in the corpus between the two studies that could affect the comparison; the Baron study included more words. It is believed, however, that the 
corpus of this study is large enough to draw significant comparisons, and is by any measure a good beginning to such studies.

Finally, the comparison of the two groups in this study, "satisfied/very helpful" and "unsatisfied/not helpful," could be compromised by a great many variables, including how long patrons have had to wait before they are assisted, how well the patrons' questions were answered, and more complex communication issues, of which language style and genre is only a part. The findings are merely correlative, however, and should not be interpreted as being causal in any way.

\section{Implications for practitioners}

Many implications for librarians staffing and managing chat reference services can be found in this study. First, and perhaps foremost, is a more empirical perception and understanding of the linguistic composition of chat reference CMC. It is indeed less formal than standard writing, but is probably not as informal as popular perception suggests. The use of emoticons, abbreviations, acronyms, and other non-verbal compensations is infrequent. And while students tend not to follow standard punctuation and capitalization, librarians do, and there appears to be no shortcoming in this practice, though further study is probably needed in this regard.

It may also be valid to suggest from this study relaxing rules of formal grammar and lexical usage is valuable when librarians chat with students of undergraduate age. As Baron writes, "[k]nowledge of contemporary CMC style (and the social control IM and

other media offer) is empowering." ${ }^{21}$ Indeed, this philosophy is much in line with what Radford has found regarding "relational facilitators"; using the linguistic style of the 
student can create a more effective reference relationship. ${ }^{22}$ Liberally using some nonverbal tokens, such as the ellipse, appears to be an effective tool in conversing with students via chat.

However, there is a distinct concern that, as Abdullah concludes, "[b]oth the process and content of [offline] writing are evolving in response to the increased use of the e-medium for writing instruction and to the language of e-communication itself.,"23 CMC is changing the way students write, and librarians, as part of the educational institutions of our society, must be sure that students "understand the difference between creativity and normative language use." ${ }^{, 24}$ While the use of an informal, spoken genre of CMC facilitates the relationship necessary for information transfer to take place successfully, it is also necessary that librarians model the language their students need to acquire.

Ultimately, this study's implication for practitioners is one of awareness; we must be aware of how we write what we write, and balance the needs for creating meaningful communication with the need for creating the same awareness of language in our students. One style does not fit all. With writing, context is everything.

\section{Conclusion}

This study creates a linguistic profile of the chat reference conversation. Validating much of the author's hypothesis, the chat reference conversation is more formal than the student-to-student IM conversation. This formality is due perhaps to its variant social relationship and the resulting social footing discrepancy. The study also validates the hypothesis that librarians write more formally than students within chat 
reference exchanges. It also appears that this form of $\mathrm{CMC}$ is also more formal than many popular accounts might suggest. It is not a formal term paper, but neither is it cryptic adolescent substandard language.

This study also partially validates the hypothesis that there is a correlation between the use of informal language by the librarian and patron satisfaction with both the librarian attending them and the service more generally. While the use of emoticons, CMC abbreviations, and CMC acronyms was not indicative of patron satisfaction, the use of non-scripted language, non-contracted lexical pairs, non-verbal compensators, and informal use of capitalization and punctuation was very indicative of how a patron perceives a librarian. The findings also suggest that "mirroring" is an effective technique in grammar and contraction formality, but not other facets of CMC.

Librarians do best to perceive chat reference CMC as a more spoken genre of language than perhaps email or other forms of written communication with students. It is not beneficial that they adopt a completely substandard dialect, but it is certainly helpful to relax the rules of standard English so the language is more useful and effective in a CMC environment. It is also incumbent upon librarians to be simply aware of their linguistic surroundings in chat reference media, so that ultimately, be it CMC or standard writing styles, students obtain the language they need to succeed in a world full of communication opportunities. 
Tables

Table 1: CMC Abbreviations

Student-to-Student (Baron)

\section{Librarian-to-Student}

Total Abbreviations

31 (of 11,718 words)

6 (of 6,787 words)

Type of Abbreviation

\begin{tabular}{lll} 
b/c OR $b c=$ because & 5 & 1 \\
\hline cya= see you & 7 & 1 \\
\hline$k=$ okay & 16 & 1 \\
\hline$r=$ are & 0 & 1 \\
\hline $4=$ for & 0 & 1 \\
\hline bf=boyfriend & 2 & 0 \\
\hline$y ?=$ why & 1 & 0 \\
\hline plz= please & 0 & 1 \\
\hline
\end{tabular}

Table 2: CMC Emoticons

\section{Student-to-Student (Baron) $\quad$ Librarian-to-Student}

Total Emoticons

49 (of 11,718 words)

6 (of 6,787 words)

Type of Emoticon

\begin{tabular}{lll}
$:)$ OR :- $=$ smiley & 31 & 3 \\
$:($ OR $:-(=$ frowny & 5 & 3 \\
\hline$:-) \quad=$ angel & 4 & 0 \\
$:-\mathrm{O}$ OR $: \mathrm{P}$ = sticking out tongue & 3 & 0 \\
\hline$:-) \quad=$ winking & 2 & 0 \\
$:-\mid \quad=$ undecided & 1 & 0 \\
$:-\quad$ = embarrassed & 1 & 0 \\
$:-\quad$ = [probably an error] & 1 & 0 \\
\hline
\end{tabular}


Table 3: Other non-verbal compensators

\section{Students \\ Librarians}

Total Compensators

34

52

Type of Compensator

\begin{tabular}{|c|c|c|}
\hline \multirow{2}{*}{$\frac{\text { Ellipse }}{\text { Dash }}$} & 18 & 43 \\
\hline & 1 & 1 \\
\hline$\frac{\text { Dash }}{\text { capitals }}$ & 10 & 3 \\
\hline multiple-punctation & 5 & 0 \\
\hline$\frac{! !+}{? ?+}$ & 3 & \\
\hline$? ?+$ & 1 & \\
\hline Utterances & 1 & \\
\hline Utterances & 0 & 5 \\
\hline "oohh" & & 1 \\
\hline "aahh" & & $\overline{1}$ \\
\hline "hmm" & & 3 \\
\hline
\end{tabular}

Table 4: Other non-verbal compensators

\begin{tabular}{|c|c|c|c|c|}
\hline & \multicolumn{2}{|c|}{ "Very Helpful" } & \multicolumn{2}{|c|}{ “Unhelpful" } \\
\hline & Librarians & Students & Librarians & Students \\
\hline Total Compensators & 44 & 11 & 8 & 23 \\
\hline \multicolumn{5}{|l|}{ Type of Compensator } \\
\hline Ellipse & 37 & 9 & 6 & 9 \\
\hline Dash & 1 & 0 & 0 & 0 \\
\hline capitals & 3 & 1 & 0 & 9 \\
\hline multiple-punctation & 0 & 1 & 0 & 4 \\
\hline$! !+$ & 0 & 1 & 0 & 2 \\
\hline$? ?+$ & 0 & 0 & 0 & 1 \\
\hline$! ?+$ & 0 & 0 & 0 & 1 \\
\hline Utterances & 3 & 0 & 2 & 0 \\
\hline "oohh" & 1 & 0 & 0 & 0 \\
\hline "aahh" & 1 & 0 & 0 & 0 \\
\hline "hmm" & 1 & 0 & 2 & 0 \\
\hline
\end{tabular}




\section{Notes and References}

${ }^{1}$ See Pew Internet \& American Life Project (2004). "How Americans Use Instant Messaging." Online. Available:

http://www.pewinternet.org/PPF/r/133/report_display.asp (January 5, 2007).

${ }^{2}$ Examples of such advice are included in Ovadia, S. "Real-Time Chat Reference and the Importance of Text-Chat." The Reference Librarian, 79/80 (2002): 157-161, Carter, D. S. "Hurry Up and Wait: Observations and Tips about the Practice of Chat Reference." The Reference Librarian, 79/80 (2002): 113-120 and Bobrowsky, T., Beck, L., Grant, M. "The Chat Reference Interview: Practicalities and Advice." The Reference Librarian, 89/90 (2005): 179-191.

${ }^{3}$ See, e.g., Radford, M. L. "Encountering Virtual Users: A Qualitative Investigation of Interpersonal Communication Chat Reference." Journal of the American Society for Information Science and Technology, 57 (2006): 1046-1059.

${ }^{4}$ This definition is from Yule, G. The Study of Language. (New York: Cambridge University Press, 1996), p. 32.

${ }^{5}$ The understanding of defining language "genre" in this study follows closely that of Voida, A., Newstetter, W. C., Mynatt, E. D. "When Conventions Collide: The Tensions of Instant Messaging Attributed." Proceedings of the SIGCHI Conference on Human Factors in Computing Systems: Changing Our World, Changing Ourselves (2002).

${ }^{6}$ Biber, D. Variation Across Speech and Writing. (New York: Cambridge University Press, c1998), p. 161.

${ }^{7}$ Ibid., p. 161.

8 "Footing" in this study is understood according to Dillon, G. L. Rhetoric as Social Imagination: Explorations in the Interpersonal Functions of Language. (Bloomington, IN: Indiana University Press, c1986).

${ }^{9}$ Baron's results are reported in Baron, N. S. "See You Online: Gender Issues in College Student use of Instant Messaging." Journal of Language \& Social Psychology 23 (2004): 397-423. 
${ }^{10}$ See http://www.askcolorado.org.

${ }^{11}$ Library Research Service. "AskColorado Continues to Grow in Second Year," (2005). Online. Available: http://www.lrs.org/documents/fastfacts/231_AskCo.pdf.

${ }^{12}$ Results were included only when transcripts and corresponding survey results could be definitively linked by IP address, exact session times, and/or patron remarks that explicitly cited librarians or interactions within transcripts. This fact is important because the transcripts were not directly tied to the survey results by any automated system.

${ }^{13}$ Radford, M. L. “Encountering Virtual Users,” 2006.

${ }^{14}$ Baron, N. S. "See You Online,” (2004), p. 411.

${ }^{15}$ Ibid., p. 397.

${ }^{16}$ Baron, N. S. "Instant Messaging and the Future of Language." Communications of the ACM, 48 (2005): 29-31, p. 31.

${ }^{17}$ Baron, N. S. "See You Online,” (2004).

${ }^{18}$ Ibid., p. 413.

${ }^{19}$ Ibid., p. 412.

${ }^{20}$ Ibid., p. 412.

${ }^{21}$ Baron, N. S. "Instant Messaging," (2005), p. 31.

${ }^{22}$ Radford, M. L. “Encountering Virtual Users,” 2006.

${ }^{23}$ Abdullah, M. H. "The Impact of Electronic Communication on Writing," ERIC Digest. (2003), p. 4.

${ }^{24}$ Baron, N. S. "Instant Messaging," (2005), p. 31. 